\title{
What happens to the sown species if a biodiversity experiment is not weeded?
}

Roscher, Christiane ; Fergus, Alexander J F ; Petermann, Jana S ; Buchmann, Nina ; Schmid, Bernhard ; Schulze, Ernst-Detlef

\begin{abstract}
Studies in experimental grasslands have extensively documented the effects of sown plant diversity on the colonization of new species, but the responses of the sown plant combinations themselves have rarely been investigated. We established experimental grasslands differing in species richness (1, $2,4,8$, and 16) and functional group number and composition (1-4; legumes, grasses, small herbs, tall herbs), and we studied the changes in the abundance of sown species (residents) in both weeded and non-weeded subplots over a period of five years after sowing. The accumulation of new species through spontaneous colonization in the non-weeded treatment did not affect the number of resident species, but had increasingly negative effects over time on the cover of resident species and their aboveground biomass production at community level. Temporal stability of resident populations was lower and yearto-year changes in resident species composition were larger in non-weeded than in weeded subplots. Compositional dissimilarity between weeded and non-weeded treatments increased through time. These negative effects of the colonization of new species on the abundances and stability of resident populations depended on resident species identity and not on additional variation between different functional groups. The colonization of new species did not change the number of resident species emerging from seeds, but reduced seedling densities of residents. Colonization did not affect the structure of resident communities as measured by species evenness, functional trait diversity and mean trait values suggesting that colonization can destabilize the species composition of residents in terms of abundance while leaving them unchanged in terms of functional characteristics. Generally, negative impacts of colonizing species on residents which accelerated through time decreased with an increasing number of sown species. Sowing more diverse grassland mixtures increases their predictability in terms of ecosystem characteristics, which is important for ecological restoration and sustainable agriculture.
\end{abstract}

DOI: https://doi.org/10.1016/j.baae.2013.01.003

Posted at the Zurich Open Repository and Archive, University of Zurich

ZORA URL: https://doi.org/10.5167/uzh-81799

Journal Article

Accepted Version

Originally published at:

Roscher, Christiane; Fergus, Alexander J F; Petermann, Jana S; Buchmann, Nina; Schmid, Bernhard; Schulze, Ernst-Detlef (2013). What happens to the sown species if a biodiversity experiment is not weeded? Basic and Applied Ecology, 14(3):187-198.

DOI: https://doi.org/10.1016/j.baae.2013.01.003 


\section{What happens to the sown species if a biodiversity experiment is not weeded?}

2

3 Christiane Roscher ${ }^{\mathrm{a}^{*}}$, Alexander J.F. Fergus ${ }^{\mathrm{b}}$, Jana S. Petermann ${ }^{\mathrm{b}, \mathrm{e}}$, Nina Buchmann, 4 Bernhard Schmid $^{\mathrm{b}}$, Ernst-Detlef Schulze ${ }^{\mathrm{d}}$

5

6 a UFZ, Helmholtz Centre for Environmental Research, Department of Community Ecology,

7 Theodor-Lieser-Strasse 4, 06120 Halle, Germany

8 b Institute of Evolutionary Biology and Environmental Studies, University of Zurich,

$9 \quad$ Winterthurerstrasse 190, 8057 Zurich, Switzerland

10 c Institute of Agricultural Sciences, ETH Zurich, Universitätsstrasse 2, 8092 Zurich, 11 Switzerland

$12{ }^{\mathrm{d}}$ Max Planck Institute for Biogeochemistry, POB 100164, 07701 Jena, Germany

13 e present address: Institute of Biology, Freie Universität Berlin, Königin-Luise-Strasse 1-3, 1414195 Berlin, Germany

15

16 *Corresponding author. Tel.: ++49 345 5585317; fax: ++49 3455585329.

17 E-mail address: christiane.roscher@ufz.de.

18

19 MS details: 300 words in abstract, 5833 words in full text, 5 figures, 1 table, Supplementary 20 Material 


\section{Abstract}

Studies in experimental grasslands have extensively documented the effects of sown plant diversity on the colonization of new species, but the responses of the sown plant combinations themselves have rarely been investigated. We established experimental grasslands differing in species richness $(1,2,4,8$, and 16) and functional group number and composition (1 to 4; legumes, grasses, small herbs, tall herbs), and we studied the changes in the abundance of sown species (= residents) in both weeded and non-weeded subplots over a period of five years after sowing. The accumulation of new species through spontaneous colonization in the non-weeded treatment did not affect the number of resident species, but had increasingly negative effects over time on the cover of resident species and their aboveground biomass production at community level. Temporal stability of resident populations was lower and year-to-year changes in resident species composition were larger in non-weeded than in weeded subplots. Compositional dissimilarity between weeded and non-weeded treatments increased through time. These negative effects of the colonization of new species on the abundances and stability of resident populations depended on resident species identity and not on additional variation between different functional groups. The colonization of new species did not change the number of resident species emerging from seeds, but reduced seedling densities of residents. Colonization did not affect the structure of resident communities as measured by species evenness, functional trait diversity and mean trait values suggesting that colonization can destabilize the species composition of residents in terms of abundance while leaving them unchanged in terms of functional characteristics. Generally, negative impacts of colonizing species on residents which accelerated through time decreased with an increasing number of sown species. Sowing more diverse grassland mixtures increases their predictability in terms of ecosystem characteristics, which is important for ecological restoration and sustainable agriculture. 
47 Keywords: biodiversity, community assembly, functional trait composition, Jena Experiment, 48 productivity, stability 


\section{Introduction}

Concerns about an accelerated loss of species diversity have stimulated an increasing interest in the potential impact of biodiversity on ecosystem processes (Hooper, Chapin, Ewel, Hector, Inchausti et al. 2005). Understanding the mechanisms that control community-level phenomena of assembly, compositional stability and resistance against invasion is essential to assess consequences of species loss. More diverse plant communities are hypothesized to have a greater resistance against invasion (Elton 1958). Increased resource capture by a diverse community, leaving fewer resources available for potential invaders, has been suggested as an explanation (Tilman 1982). Invading species themselves may affect ecosystem processes by modifying species interactions and altering the structure and composition of the established communities (Meiners, Pickett \& Cadenasso 2001, Yurkonis, Meiners \& Wacholder 2005). Invaders may affect the resident community by inhibiting germination and establishment of new individuals belonging to the resident community (Crawley, Brown, Heard \& Edwards 1999). Invaders may also displace established individuals of resident species through resource competition or the development of antagonistic soil microbial feedbacks (Theoharides \& Dukes 2007). The effects of invaders may depend on their identity and that of residents, however, effects at the species level may not necessarily translate into community processes (Yurkonis et al. 2005).

In spite of controversies over the interpretation of results about diversity-invasion resistance relationships obtained in observational and experimental studies (Fridley, Stachowicz, Naeem, Sax, Seabloom et al. 2007), similar mechanisms are supposed to explain the suppression of invaders of non-resident species by more diverse communities in natural and experimental systems. A number of biodiversity experiments have investigated the effects of species richness on the spontaneous colonization of new species at single or multiple points in time (e.g. Knops, Tilman, Haddad, Naeem, Mitchell et al. 1999, van Ruijven, de Deyn \& Berendse 2003, Roscher, Beßler, Oelmann, Engels, Wilcke et al. 2009a). Less is known about 
the response of the resident species themselves once a community is open to colonization by unsown species. Some studies reported a rapid loss of resident species in highly diverse mixtures in the first years after cessation of weeding (Pfisterer, Joshi, Schmid \& Fischer 2004, Rixen, Huovinen, Huovinen, Stöckli \& Schmid 2008) or when high-diversity mixtures were established on arable land (Lepš, Doležal, Bezemer, Brown, Hedlund et al. 2007). Such experiments did not include a weeded control and therefore lack the direct comparison of weeded vs. non-weeded artificially established communities. This distinction may have important implications for the evaluation of results obtained in numerous biodiversity experiments (Hooper et al. 2005), many of which have been criticized for immaturity of plant communities, their random species selection and the continuous manipulation required to maintain the designed species compositions (Wardle 2001, Lepš 2004). In addition, land-use changes are among the most important drivers of global biodiversity and intensification of land-use is thought to reduce the diversity and composition of biological communities (Schläpfer, Schmid \& Seidl 1999). Therefore, developing strategies to maintain, create or reassemble communities resistant to biological invasion is a major challenge for ecological restoration (Funk, Cleland, Suding \& Zavaleta 2008).

In an initial report of a study comparing a weeded and a non-weeded treatment in experimental grassland communities sown at different plant diversity levels (Jena Experiment; Roscher, Schumacher, Baade, Wilcke, Gleixner et al. 2004), we showed that the number and the abundance distribution of established resident species as well as their productivity were similar in both treatments in the first two years after sowing (Roscher, Temperton, Buchmann \& Schulze 2009b). Here, we expand this study to look at the longerterm effects of colonizing species on the composition of resident species and their productivity over a 5-year time span. Based on the expectation that the impact of newly colonizing species accelerates through time in the non-weeded treatment by altering resource dynamics and species interactions we tested the following hypotheses: (1) Temporal stability 
102 in population- and community-level characteristics of residents is lower in non-weeded

103 communities than in weeded communities. (2) Extinctions or reductions in the abundances of

104 resident species are more pronounced in non-weeded communities. (3) Cover and

105 productivity of residents are lower in non-weeded communities. (4) Shifts in species

106 abundance distributions reduce evenness and functional trait diversity of residents in non-

107 weeded communities because subordinate species are at a greater risk for displacement by

108 newly colonizing species. (5) Differences in population and community characteristics of 109 residents between non-weeded and weeded communities decrease with increasing richness of 110 resident species.

112 Material and Methods

\section{Study site and experimental design}

115 This study is part of a large biodiversity experiment (Jena Experiment; Roscher et al. 2004).

116 The experimental site is situated in the floodplain of the river Saale at the northern edge of

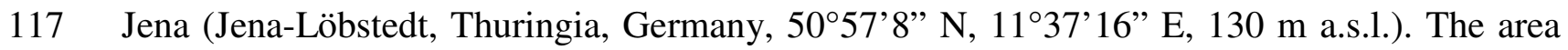

118 around Jena is characterized by a mean annual air temperature of $9.3{ }^{\circ} \mathrm{C}$ and mean annual 119 precipitation of $587 \mathrm{~mm}$ (Kluge \& Müller-Westermeier 2000). The soil of the experimental 120 site is a Eutric Fluvisol developed from up to $2 \mathrm{~m}$ thick loamy fluvial sediments. Soil texture 121 ranges from sandy loam near the river to silty clay with increasing distance from the river.

122 A pool of 60 species common in Molinio-Arrhenatheretea grasslands (semi-natural Central 123 European mesophilic grasslands, Ellenberg 1988) was chosen for the experiment. These 124 species were categorized into four functional groups: grasses (16 species), small herbs (12 125 species), tall herbs (20 species), and legumes (12 species). In total, the Jena Experiment 126 comprises 78 plots of a size of $20 \times 20 \mathrm{~m}$, which cover a gradient in species richness $(1,2,4$, 1278 , and 16) and functional group richness (1, 2, 3, and 4), the latter being near orthogonal to 
species richness. Mixtures were created by random draws with replacement. Each speciesrichness level was established on 16 large plots, except for the 16-species-richness level which was established on 14 large plots (because the species number in the legume and the small herb functional groups was too low for pure 16-species mixtures). In addition, two replicated monocultures of each experimental species were established on smaller plots of 3.5 $\times 3.5 \mathrm{~m}$. Plots were sown with a constant total density of 1000 germinable seeds per $\mathrm{m}^{2}$ distributed equally among species in mixtures. The experimental plots were arranged in four blocks parallel to the riverside to account for the gradient in soil characteristics.

Within each large plot, two subplots of $2.00 \times 2.25 \mathrm{~m}$ size separated by $0.3 \mathrm{~m}$ between one another were established near to the plot margin (excluding the outer $0.5 \mathrm{~m}$ buffer) shortly after the biodiversity experiment was sown in 2002. One of these subplots was weeded regularly as the main experiment (April, July). The other subplot was never weeded after sowing. Plots were mown twice each year (early June, September) and mown biomass was removed. The weeded control subplot was maintained until 2007.

\section{Data collection}

Aboveground biomass was harvested twice per year at estimated peak standing biomass (late May, August) just prior to mowing during the study period (2003-2007). The vegetation was clipped at $3 \mathrm{~cm}$ aboveground in a randomly located rectangle of $0.2 \times 0.5 \mathrm{~m}$ size in each subplot. Biomass was sorted into total resident (= sown) species, total colonizer species and detached dead plant material. Samples were weighed after being dried to a constant weight $\left(70{ }^{\circ} \mathrm{C}, 48 \mathrm{~h}\right.$ ). Total cover of resident and colonizer species was visually estimated to the nearest percentage before weeding (April, July) and again at estimated peak biomass (late May, August). Species cover was recorded twice per year directly before biomass harvest using a modified Londo scale (Londo 1976). Numerical values for species cover were coded as $0.5(<1 \%), 3(1-5 \%) 10$ (6-15\%), 20 (16-25\%), 30 (26-35\%), 40 (36-45\%), 50 (46-55\%), 
60 (56-65\%), 70 (66-75\%), 80 (76-85\%), and 90 (>85\%). Seedlings (plant individuals with cotyledons) of resident species were counted three times in 2006 (April, July, October). Three quadrats $(0.3 \times 0.3 \mathrm{~m})$ per subplot were randomly placed for each census. Although it is not possible with this procedure to completely exclude the emergence of additional seedlings between these three time points (underestimation of seedling densities) or the persistence of seedlings for a longer period in this stage (overestimation of seedling densities), seedling densities per $\mathrm{m}^{2}$ were calculated for each subplot based on pooled data from all census points. Aboveground plant traits were measured in monocultures of each species in May and August 2004. These traits were plant height, specific leaf area (SLA), leaf nitrogen concentration $\left(\mathrm{N}_{\mathrm{M}}\right)$ and shoot biomass: $\mathrm{N}$ ratios. Root characteristics (root depth, root type) were compiled as categorical variables from the literature (see Roscher et al. 2004 for details).

\section{Data analyses}

First, plant trait data and relative abundances of resident species were used to calculate community-weighted mean traits (CWMs; Garnier, Cortez, Billès, Navas, Roumet et al. 2004) and functional trait diversity $\left(\mathrm{FD}_{\mathrm{Q}}\right)$ using Rao`s quadratic diversity (Rao`s Q; Rao 1982) for each subplot. Second, cover abundances of resident species were used to derive Shannon`s evenness J', which is known to give greater weight to rare species, and Simpson`s index of evenness $E_{1 / D}$, which gives more weight to abundant species (Smith \& Wilson 1996). Third, cover values were used to compute Bray-Curtis distances (Bray \& Curtis 1957) for resident species as a measure of compositional dissimilarity (1) between non-weeded vs. weeded subplot pairs per sampling date, and (2) per subplot to assess year-to-year compositional changes. All calculations were completed separately for data recorded in early summer (May) and late summer (August) and averaged to obtain mean values for each year (for details see Appendix A).

To evaluate effects of non-weeding vs. weeding, the log response ratio 


$$
\operatorname{lnRR}{ }_{X}=\ln \left(X_{\text {non-weeded }} / X_{\text {weeded }}\right)
$$

181 (Hedges, Gurevitch \& Curtis 1999) was computed between non-weeded vs. weeded subplots

182 for all variables. Positive values of $\operatorname{lnRR}_{X}$ indicate that the studied variable increased in

183 response to non-weeding, while negative $\ln R R_{X}$-values indicate a decrease in response to

184 non-weeding. The coefficient of variation $(=\mathrm{CV})$ was calculated as a measure of temporal

185 variability (McCann 2000) based on annual values of resident community characteristics and

186 species abundances in weeded and non-weeded subplots (2003-2007).

187 Generalized linear models (type-I sum of squares) were used to test the effects of block, sown 188 species richness (SR, log-linear term) and functional group number (FG, linear term) on 189 variables measured at the plot level. In analyses of CVs, a split-plot term for non-weeded vs. 190 weeded subplots, and in analyses of $\operatorname{lnRR}$, a term for repeated measures and their interactions 191 with SR and FG were entered. In a series of alternative models, contrasts for the presence of 192 each functional group (legumes, grasses, small herbs, tall herbs) were fitted after SR and FG.

193 To account for the unbalanced occurrences of sown species in the experimental plots, mixed 194 effects models were applied in analyses of CVs and lnRR of individual species. Block and 195 plot identity were entered as random effects in a nested sequence. Starting from a constant 196 null model, terms for sown species richness (SR, log-linear), species identity, SR $\times$ species 197 identity, weeding treatment and time, plus their interactions with SR and species identity were 198 added sequentially as fixed factors. In alternative models, species identity was replaced by 199 terms for functional group identity or contrasts for each functional group. The maximum 200 likelihood method was applied, and likelihood ratio tests (= L ratio) were used to assess the 201 statistical significance of model improvement. Data analysis was performed with the 202 statistical software R2.11.1 (R Development Core Team, http://www.R-project.org), the 203 implemented packages nlme (Pinheiro, Bates, DebRoy, Sakar \& R Core Team 2009) and FD 204 (Laliberté \& Shipley 2010). 


\section{Results}

\section{Resident species richness}

The temporal variability (measured as $\mathrm{CV}$ ) of resident species richness increased with the number of sown species (Appendix A: Table S1, Fig. 1A). Log response ratios in resident

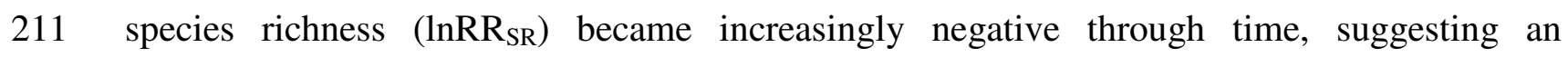
212 increasing loss of resident species in the non-weeded subplots (Fig. 1B). Species loss was 213 accelerated by legume presence in the sown species combinations (increasingly negative $214 \quad \operatorname{lnRR} R_{S R}$ over time), while species loss was less pronounced in communities with small herbs. 215 However, $\operatorname{lnRR} R_{\mathrm{SR}}$ was not different from zero across the study period, indicating no 216 significant differences in resident species richness between weeded and non-weeded subplots.

\section{Resident species abundance}

219 The average temporal variability in resident species abundance increased with the number of 220 sown species (Table S1, Fig. 1C). The temporal variability in resident species abundances was 221 higher in non-weeded subplots, especially in communities with a lower number of sown 222 species. Log response ratios of resident species abundances $\left(\ln R R_{\text {Pop }}\right)$ were significantly 223 different from zero in all study years (with exception of 2004, Fig. 1D), indicating lower 224 abundances of resident species in non-weeded compared to weeded subplots. Generally, 225 differences in species abundances between weeded and non-weeded subplots decreased with a 226 higher number of sown species (less negative $\ln R R_{\text {Pop }}$ ). The deviation in species abundances 227 in non-weeded from weeded subplots increased through time, particularly in communities 228 with a lower number of sown species (more negative $\operatorname{lnR} R_{\text {Pop }}$, Table $S 1$ ).

229 Analyses at the species-level showed that the temporal variability in species abundances 230 depended on species and functional group identity (Table 1). Effects of weeding vs. non231 weeding on species temporal variability was not significantly different among species (Table 
232 1). Differences in species abundances in response to weeding and their changes through time

233 (i.e., $\operatorname{lnRR} R_{\text {Pop }}$ at species-level) were also dependent on species identity (Table 1). In total, only

2345 out of 60 species had $\operatorname{lnRR}_{\text {Pop }}$ significantly $<0$, i.e. lower abundances in non-weeded

235 subplots, across all species-richness levels in last study year (see Appendix A: Fig. S1). The

$236 \operatorname{lnRR}_{\text {Pop }}$ was highly variable, but mostly negative, for other species.

\section{Resident community cover and biomass production}

239 Temporal variability in resident community cover and biomass production decreased with the

240 number of sown species (Table S1, Fig. 1E, G). On average, temporal variability in resident

241 community cover and biomass production was larger in non-weeded subplots, but differences

242 between weeding treatments decreased with increasing numbers of sown species (Table S1).

243 Log response ratios closer to zero in resident community cover $\left(\ln R R_{\text {Cov }}\right)$ and biomass 244 production $\left(\operatorname{lnRR} R_{\text {Biom }}\right)$ indicated decreased differences between weeding treatments with

245 increasing number of sown species (Table $\mathrm{S} 1$, Fig. $1 \mathrm{~F}, \mathrm{H})$. On average, $\operatorname{lnRR} R_{\text {Cov }}$ and $\ln R R_{\text {Biom }}$ 246 decreased through time, but the decline in $\ln R R_{\text {Cov }}$ was stronger when there were fewer sown 247 species. From 2006 onwards, $\operatorname{lnR} R_{\text {Cov }}$ and $\operatorname{lnR} R_{\text {Biom }}$ were significantly lower than zero, 248 indicating a lower community cover and biomass production in non-weeded compared to 249 weeded subplots across all species-richness levels (Fig. 1F, H).

\section{Number of germinating species and seedling density of resident species}

252 The $\log$ response ratio of the number of germinating resident species $\left(\ln R R_{\text {SRgerm }}\right)$ based on 253 three censuses in 2006 was not significantly different from zero (test for overall mean $\neq 0$ : $\left.254 \mathrm{~F}_{1,72}=0.33, \mathrm{p}=0.568\right)$, suggesting that weeding treatments did not affect the number of germinating resident species (Fig. 2A) irrespective of sown species richness $\left(\mathrm{F}_{1,72}=0.90, \mathrm{p}=\right.$ $0.346)$ or functional group number $\left(\mathrm{F}_{1,72}=0.05, \mathrm{p}=0.832\right)$. The log response ratio of seedling densities of resident species $\left(\ln R R_{\text {Seed }}\right)$ was significantly lower than zero (test for overall 
mean $\left.\neq 0: F_{1,72}=9.78, p=0.003\right)$, indicating that less resident seedlings emerged in the nonweeded subplots (Fig. 2B). The reduction of seedling emergence in non-weeded compared to weeded subplots did not depend on sown species richness $\left(\mathrm{F}_{1,72}=0.94, \mathrm{p}=0.336\right)$ or functional group number $\left(\mathrm{F}_{1,72}=0.10, \mathrm{p}=0.758\right)$.

\section{Compositional dissimilarity of resident species combinations}

264 Compositional dissimilarity of resident species combinations (Bray-Curtis distances) between weeded and non-weeded subplots decreased with sown species richness $\left(\mathrm{F}_{1,72}=11.93, \mathrm{p}=\right.$ 0.001), while functional group number or the presence of particular plant functional groups did not affect this compositional dissimilarity. Bray-Curtis distances between weeded and non-weeded treatments increased through time $\left(\mathrm{F}_{1,75}=64.58, \mathrm{p}<0.001\right)$. This increase in dissimilarity was larger in species-poor compared to species-rich communities $\left(\mathrm{F}_{1,75}=23.61\right.$, $\mathrm{p}<0.001$, Fig. 3).

Temporal variability in resident species composition (= CV of Bray-Curtis distances) decreased with increasing number of sown species, while functional group number, the presence of particular plant functional groups or weeding treatments did not affect temporal variability in composition (Appendix A: Table S2, Fig. 4A). Differences in temporal changes in terms of composition between weeded and non-weeded subplots decreased with increasing number of sown species (decreasing $\operatorname{lnR} R_{\text {Comp }}$, Table $S 2$ ), but they became stronger through time (Table S2). The $\operatorname{lnRR}_{\text {Comp }}$ from 2006 to 2007 was significantly larger than zero, suggesting that temporal changes in non-weeded subplots exceeded those in weeded subplots across all species-richness levels (Fig. 4B).

\section{Evenness of resident species combinations}

282 The temporal variability of the Shannon evenness $\left(\mathrm{J}^{`}\right)$ decreased with increasing sown species

283 richness, while the $\mathrm{CV}$ of the Simpson index of evenness $\left(\mathrm{E}_{1 / \mathrm{D}}\right)$ was not influenced by species 
284 richness, indicating that species-rich communities had a more stable species abundance 285 distribution of subordinate species (Table S2, Fig. 4C, D). The temporal variability of J and $286 \mathrm{E}_{1 / \mathrm{D}}$ did not differ between weeded and non-weeded subplots. Differences in $\mathrm{J}$ between weeding treatments decreased at higher sown species-richness levels (increasing $\ln R R_{\text {Shan }}$, Table S2, Fig. 4D). In general, weeded and non-weeded subplots did not differ significantly in species evenness in the 5-year study (Fig. 4D, F), except for a higher $\mathrm{E}_{1 / \mathrm{D}}$ across all species290 richness levels in the non-weeded subplots in 2007 (lnRR $\operatorname{limp}_{\text {Sim }}>0$; Fig. 4F).

\section{Functional trait diversity and aggregated traits of resident species combinations}

Temporal variability in single-trait as well as in multiple-trait functional diversity $\mathrm{FD}_{\mathrm{Q}}$ decreased with an increasing number of sown species or functional groups, with the exception of $\mathrm{FD}_{\mathrm{Q}}$ in root depth (Appendix A: Table S3, Fig. 4G). Temporal variability in communityweighted means of trait values (CWM) did not depend on sown species richness, but increasing functional group richness was coupled with increased temporal variability in community-weighted leaf nitrogen concentrations $\left(\mathrm{N}_{\mathrm{M}}\right)$ and shoot biomass: $\mathrm{N}$ ratios (Table S3). Temporal variability in functional trait composition $\left(\mathrm{CWM}\right.$ and $\left.\mathrm{FD}_{\mathrm{Q}}\right)$ was not influenced

300 by weeding (Table S3). Log response ratios $\left(\ln R R_{\mathrm{CWM}}, \ln R R_{\mathrm{FDQ}}\right)$ were not significantly different from zero (test for overall mean $\neq 0: p>0.05$ ), indicating that functional trait composition of residents between weeded and non-weeded subplots across all speciesrichness levels did not differ (Fig. $4 \mathrm{H}$ ). However, $\operatorname{lnR} R_{\mathrm{FDQ}}$ in multiple traits, but also $\ln R \mathrm{R}_{\mathrm{FDQ}}$

304 in single traits such as $\mathrm{N}_{\mathrm{M}}$ and shoot height, became increasingly negative at lower sown 305 species richness, suggesting that non-weeding had negative effects on $\mathrm{FD}_{\mathrm{Q}}$ (Table S3, Fig. $4 \mathrm{H})$.

\section{Cover and species number of colonizers}

309 On average, colonizer cover and the number of colonizing species decreased with increasing 
sown species richness (Appendix A: Table S4, Fig. 5). Weeding reduced colonizer cover and

311 colonizer species number. Effects of weeding on colonizer cover did not depend on sown

312 species richness, while colonizer species numbers were more successfully reduced through

313 weeding at increasing species richness (Table S4). Overall, colonizer cover and species

314 numbers increased with increasing time after sowing of the biodiversity experiment. Weeding

315 did not prevent the establishment of a higher number of colonizer species through time, while

316 the increase in colonizer cover through time was less pronounced when communities were 317 weeded (Table S4).

\section{Discussion}

320 The goal of the present study was to test what would happen to the sown species over several 321 years if a biodiversity experiment was not weeded. Typically, most plant biodiversity experiments weed unwanted species in order to maintain sown species-richness levels and community composition (for an exception, see Niklaus, Leadley, Schmid \& Körner 2001).

This is justified as the simulated extinction of all other species from a community (Schmid \& Hector 2004). However, weeding may be seen as an undesirable disturbance or unusual management practice (Wardle 2001, Lepš 2004) generating doubt about whether similar results would be observed if biodiversity experiments were not weeded. Our study comparing weeded and non-weeded subplots in a grassland biodiversity experiment showed that newly colonizing species may reduce the temporal stability of resident population- and community-

330 level characteristics (confirming hypothesis 1). While species and community cover as well as 331 productivity were reduced in non-weeded communities (confirming hypotheses 2 and 3 ), the shift in abundance distribution had minor effects on community characteristics such as 333 evenness and functional trait composition (rejecting hypothesis 4). In general, impacts of 334 colonization by new species were moderate in communities with higher species richness, 
while their negative effects became more severe in communities with lower species richness over several years (confirming hypothesis 5).

337 Negative effects of newly colonizing species on community structure and composition of 338 resident species may involve direct competitive displacement as well as inhibition of 339 establishment of new individuals. The competition-colonization model (Tilman 1994) is 340 based on the assumption that resident species are excluded and the local diversity is reduced 341 when competitive, dominant species are introduced. In our study, resident species numbers in 342 weeded and non-weeded subplots were not different, but tended to diverge over the 5-year 343 study period. However, a higher sown diversity increased the temporal variability of resident 344 species numbers irrespective of weeding (Fig. 1A). This suggests that observations of 345 increased species extinctions at higher species richness after cessation of weeding in studies 346 lacking a continuously weeded control (Pfisterer et al. 2004, Rixen et al. 2008) may not necessarily have been caused by the colonization of new species but by a reduced 348 compositional stability of communities with a higher number of less stable subordinate 349 species (Foster, Smith, Dickson \& Hildebrand 2002, Roscher, Weigelt, Proulx, Marquard, 350 Schumacher et al. 2011). In addition, the pressure of colonizers might have been larger in 351 previous experiments with smaller plots (Pfisterer et al. 2004, Rixen et al. 2008), while the non-weeded subplots in the large plots of Jena Experiment were surrounded by a weeded area 353 with the same sown species combinations.

354 In contrast to negligible effects of weeding treatments on the numbers of resident species, 355 average resident species cover was lower in non-weeded communities and compositional 356 divergence between weeding treatments increased through time. As a consequence, non357 weeded communities had on average a lower stability in biomass production and total plant 358 cover of residents compared to weeded communities (Fig. 1E, G). However, temporal 359 stability in productivity and cover of residents was positively related to sown plant diversity 
360 irrespective of weeding, which is in line with a previous study by Bezemer \& van der Putten 361 (2007) on ex-arable land.

362 One possible explanation for the reduction of resident species abundances and community

363 biomass is resource competition between residents and colonizers. The availability of light 364 and soil resources have been shown to regulate the success of colonizing species in several 365 experimental studies in grasslands (e.g. Davis, Grime \& Thompson 2000, Roscher et al. 366 2009a). Grime (2006) predicted that traits associated with competition are more common in 367 relatively undisturbed, productive environments, because species with traits associated with poor competitive ability are likely to be competitively excluded. Under nutrient-rich conditions fast growth is a prerequisite for high competitive ability. Specific leaf area and leaf 370 nitrogen concentrations correlate positively with relative growth rates (e.g. van der Werf, van 371 Nuenen, Visser \& Lambers 1993). In addition, plant height is an important indicator for species competitive ability (Gaudet \& Keddy 1988). In our study, the spontaneous 373 colonization of new species had only minor impacts on trait composition of dominant species 374 as shown by the non-significant differences in community-weighted means of traits related to 375 competitive ability between weeded and non-weeded communities. Only at lower levels of 376 sown plant diversity did colonizing species have negative impacts on the diversity of light377 (plant height) and nitrogen-acquisition strategies of the resident species (more negative values 378 of $\operatorname{lnRR} \mathrm{FDQ}_{\mathrm{F}}$, Fig. $4 \mathrm{H}$, Table S3), suggesting that the accumulation of more colonizers reduced 379 niche diversification among residents.

380 Negative soil feedbacks, i.e. the accumulation of pathogens, parasites or herbivores of roots 381 (Bever, Westover \& Antonovics 1997), provide an alternative explanation for a declining 382 performance of residents in our long-term experiment. Relative species abundances in plant communities may decline through reduced competitive ability when species are growing on

384 the same soil for an extended time (Klironomos 2002, Petermann, Fergus, Turnbull \& Schmid 385 2008). The composition of soil organisms is likely to differ between non-weeded and weeded 
communities, where the removal of unwanted species causes soil disturbances and therefore could reduce the potential for negative soil feedbacks. A lower competitive ability of residents through antagonistic interactions with soil organisms would also favour the competitive displacement of residents through the accumulation of new colonizers in non-weeded communities. In addition, negative soil feedbacks could explain why reductions in the 391 abundance of residents in non-weeded communities were common across nearly all 392 experimental species and not restricted to subordinate species with lower ability for resource 393 competition (Fig. S1).

394 Reduced establishment of new individuals of residents could further increase negative effects 395 of colonizers in non-weeded communities in the long term. Higher seedling numbers of 396 resident species in weeded communities (Fig. 2B) could be attributable to either a close 397 relationship between reduced population sizes and propagule accumulation in non-weeded 398 communities, a stimulation of germination caused by soil disturbance during weeding (Leck, 399 Parker \& Simpson 1989), or the limitation of favourable microsites for germination in non400 weeded plant communities, which had a higher total plant cover (analysis not shown).

401 The colonization of new species apparently prevented single species from attaining extensive 402 dominance. In the long term, the Simpson index of evenness, which gives greater weight to 403 abundant species, was higher in non-weeded than in weeded communities (Fig. 4F). In 404 contrast, at lower species richness, the Shannon evenness, which accords rare species greater 405 weight, was lower in non-weeded communities (Fig. 4D). Therefore, those resident species 406 that occurred in low abundances were acutely impeded by the colonization of new species in 407 communities of lower sown species richness. This consolidates the decreasing functional trait 408 diversity in non-weeded communities in our study and the non-random species extinction 409 scenarios in natural ecosystems (Zavaleta \& Hulvey 2004). Several removal experiments in 410 natural grasslands and abandoned agricultural land have shown that the effects of removal of 411 single species or functional groups on compensatory growth, the colonization of new species 
and subsequent community structure is dependent on the identity of the removed and the

413 remaining species (e.g. Munson \& Lauenroth 2009, McLaren \& Turkington 2011).

414 In summary, the observed changes in the abundance distribution of resident species and the 415 compositional divergence between weeded and non-weeded communities suggest that the 416 impact of colonizing species on resident species accelerates through time, particularly in 417 communities with fewer initially sown species. It is well known from several studies in 418 weeded experimental grasslands that their temporal stability increases with species richness 419 (e.g. Tilman, Reich \& Knops 2006, Roscher et al. 2011). Our study adds information showing 420 that the patterns observed in weeded communities only apply at higher sown diversity when 421 colonizing species are not removed through weeding. This is important for the evaluation of 422 results obtained in biodiversity experiments and their implications for restoration and 423 sustainable agriculture. Sowing more diverse grassland mixtures increases their predictability 424 in terms of ecosystem characteristics such as productivity as well as their species and 425 functional composition, which is critically important for interactions with organisms at higher 426 trophic levels, which are usually more dependent on species composition than on intrinsic 427 richness.

\section{Acknowledgements}

430 The Jena Experiment is funded by the German Science Foundation (FOR 456) with additional 431 support from the Max Planck Society and the Friedrich Schiller University of Jena and 432 coordinated by W.W. Weisser. B.S. was additionally supported by the Swiss National Science 433 Foundation (310030E-131193). We thank V.M. Temperton for the provision of biomass data. 434 We acknowledge U. Wehmeier, S. Junghans, S. Hengelhaupt, A. Oswald, U. Gerighausen and 435 many student helpers for their support with the maintenance of the invasion experiment, 436 harvest of biomass, measurement of plant traits and sample preparation for chemical analysis. 437 I. Hilke carried out elemental analyses. 


\section{Appendix A. Supplementary data}

440 Supplementary data associated with this article can be found, in the online version, at XXXX.

\section{References}

443 Bever, J.D., Westover, K.M., \& Antonovics, J. (1997). Incorporating the soil community into 444 plant population dynamics: the utility of the feedback approach. Journal of Ecology, 85, 561445573.

446 Bezemer, T.M., \& van der Putten, W.H. (2007). Diversity and stability in plant communities. $447 \quad$ Nature, 446, E6-E8.

448 Bray, J.R., \& Curtis, J.T. (1957). An ordination of the upland forest communities of southern 449 Wisconsin. Ecological Monographs, 27, 325-349.

450 Crawley, M.J., Brown, S.L., Heard, M.S., \& Edwards, G.R. (1999). Invasion-resistance in 451 experimental grassland communities: species richness or species identity? Ecology Letters, 2, $452 \quad 140-148$.

453 Davis, M.A., Grime, J.P., \& Thompson, K. (2000). Fluctuating resources in plant 454 communities: a general theory of invasibility. Journal of Ecology, 88, 528-534.

455 Ellenberg, H. (1988). Vegetation ecology of Central Europe. Cambridge: Cambridge 456 University Press.

457 Elton, C.S. (1958). The ecology of invasions by animals and plants. London: Methuen.

458 Foster, B.L., Smith, V.H., Dickson, T.L., \& Hildebrand, T. (2002). Invasibility and 459 compositional stability in a grassland community: relationships to diversity and extrinsic 460 factors. Oikos, 99, 300-307.

461 Fridley, J.D., Stachowicz, J.J., Naeem, S., Sax, D.F., Seabloom, E.W., Smith, M.D., 462 Stohlgren, T.J., Tilman, D., \& von Holle, B. (2007). The invasion paradox: reconciling 463 pattern and process in species invasion. Ecology, 88, 3-17. 
464 Funk, J.L., Cleland, E.E., Suding, K.N., \& Zavaleta, E.S. (2008). Restoration through 465 reassembly: plant traits and invasion resistance. Trends in Ecology and Evolution, 23, 695466703.

467 Garnier, E., Cortez, J., Billès, G., Navas, M.-L., Roumet, C., Debussche, M., Laurent, G., 468 Blanchard, A., Aubry, D., Bellmann, A., Neill, C., \& Toussaint, J.-P. (2004). Plant functional 469 markers capture ecosystem properties during secondary succession. Ecology, 85, 2630-2637.

470 Gaudet, C.L., \& Keddy, P.A. (1988). A comparative approach to predicting competitive 471 ability from plant traits. Nature, 334, 242-243.

472 Grime, J.P. (2006). Trait convergence and trait divergence in herbaceous plant communities: 473 mechanisms and consequences. Journal of Vegetation Science, 17, 255-260.

474 Hedges, L.V., Gurevitch, J., \& Curtis, P.S. (1999). The meta-analysis of response ratios in 475 experimental ecology. Ecology, 80, 1150-1156.

476 Hooper, D.U., Chapin, F.S., Ewel, J.J., Hector, A., Inchausti, P., Lavorel, S., Lawton, J.H., 477 Lodge, D.M., Loreau, M., Naeem, S., Schmid, B., Setälä, H., Symstad, A.J., Vandermeer, J., 478 \& Wardle, D.A. (2005). Effects of biodiversity on ecosystem functioning: A consensus of 479 current knowledge. Ecological Monographs, 75, 3-35.

480 Klironomos, J.N. (2002). Feedback with soil biota contributes to plant rarity and invasiveness 481 in communities. Nature, 417, 67-70.

482 Kluge, G., \& Müller-Westermeier, G. (2000). Das Klima ausgewählter Orte der 483 Bundesrepublik Deutschland: Jena. Berichte des Deutschen Wetterdienstes, 213, 1-290.

484 Knops, J.M.H., Tilman, D., Haddad, N.M., Naeem, S., Mitchell, C.E., Haarstad, J., Ritchie, 485 M.E., Howe, K.M., Reich, P.B., Siemann, E., \& Groth, J. (1999). Effects of plant species 486 richness on invasion dynamics, disease outbreaks, insect abundances and diversity. Ecology 487 Letters, 2, 286-293.

488 Laliberté, E., \& Shipley, B. (2010). FD: measuring functional diversity (FD) from multiple 489 traits, and other tools for functional ecology. $\mathrm{R}$ package version 1.0-9. Available at 
490

491

492

493

494

495

496

497

498

499

500

501

502

503

504

505

506

507

508

509

510

511

512

513

http://www.r-project.org.

Leck, M.A., Parker, V.T., \& Simpson, R.L. (1989). Ecology of soil seed banks. New York: Academic Press.

Lepš, J. (2004). What do the biodiversity experiments tell us about consequences of plant species loss in the real world? Basic and Applied Ecology, 5, 529-534.

Lepš, J., Doležal, J., Bezemer, T.M., Brown, V.K., Hedlund, K., Igual Arroyo, M., Jörgensen, H.B., Lawson, C.S., Mortimer, S.R., Peix Geldart, A., Rodríguez Barrueco, C., Santa Regina, I., Šmilauer, P., \& van der Putten, W.H. (2007). Long-term effectiveness of sowing high and low diversity seed mixtures to enhance plant community development on ex-arable fields. Applied Vegetation Science, 10, 97-110.

Londo, G. (1976). The decimal scale for releves of permanent quadrats. Vegetatio, 33, 61-64. McCann, K.S. (2000). The diversity-stability debate. Nature, 405, 228-233.

McLaren, J.R., \& Turkington, R. (2011). Biomass compensation and plant responses to 7 years of plant functional group removals. Journal of Vegetation Science, 22, 503-515.

Meiners, S.J., Pickett, S.T.A., \& Cadenasso, M.L. (2001). Effects of plant invasions on the species richness of abandoned agricultural land. Ecography, 24, 633-644.

Munson, S.M., \& Lauenroth, W.K. (2009). Plant population and community responses to removal of dominant species in the shortgrass steppe. Journal of Vegetation Science, 20, 224232.

Niklaus, P.A., Leadley, P.W., Schmid, B., \& Körner, C. (2001). A long-term field study on biodiversity x elevated $\mathrm{CO}_{2}$ interactions in grassland. Ecological Monographs, 71, 341-356.

Petermann, J.S., Fergus, A.J.F., Turnbull, L.A., \& Schmid, B. (2008). Janzen-Connell effects are widespread and strong enough to maintain diversity in grasslands. Ecology, 89, 23992406. 
514 Pfisterer, A.B., Joshi, J., Schmid, B., \& Fischer, M. (2004). Rapid decay of diversity-

515 productivity relationships after invasion of experimental plant communities. Basic and 516 Applied Ecology, 5, 5-14.

517 Pinheiro, J., Bates, D., DebRoy, S., Sakar, D., \& R Core Team (2009). nlme: linear and 518 nonlinear mixed effects models. R package version 3.1-96. Available at http://www.r519 project.org.

520 Rao, C.R. (1982). Diversity and dissimilarity coefficients: a unified approach. Theoretical 521 Population Biology, 21, 24-43.

522 Rixen, C., Huovinen, C., Huovinen, K., Stöckli, V. \& Schmid, B. (2008). A plant diversity $\times$ 523 water chemistry experiment in subalpine grassland. Perspectives in Plant Ecology, Evolution 524 and Systematics, 10, 51-61.

525 Roscher, C., Schumacher, J., Baade, J., Wilcke, W., Gleixner, G., Weisser, W.W., Schmid, 526 B., \& Schulze, E.-D. (2004). The role of biodiversity for element cycling and trophic 527 interactions: an experimental approach in a grassland community. Basic and Applied Ecology, $528 \quad 5,107-121$.

529 Roscher, C., Beßler, H., Oelmann, Y., Engels, C., Wilcke, W., \& Schulze, E.-D. (2009a). 530 Resources, recruitment limitation and invader species identity determine pattern of 531 spontaneous invasion in experimental grasslands. Journal of Ecology, 97, 32-47.

532 Roscher, C., Temperton, V.M., Buchmann, N., \& Schulze, E.-D. (2009b). Community 533 assembly and biomass production in regularly and never weeded experimental grasslands.

534 Acta Oecologica, 35, 206-217.

535 Roscher, C., Weigelt, A., Proulx, R., Marquard, E., Schumacher, J., Weisser, W.W., \& 536 Schmid, B. (2011). Identifying population- and community-level mechanisms of diversity537 stability relationships in experimental grasslands. Journal of Ecology, 99, 1460-1469.

538 Schläpfer, F., Schmid, B., \& Seidl, I. (1999). Expert estimates about effects of biodiversity on 539 ecosystem processes and services. Oikos, 84, 346-352. 
540 Schmid, B., \& Hector, A. (2004). The value of biodiversity experiments. Basic and Applied 541 Ecology, 5, 535-542.

542 Smith, B., \& Wilson, J.B. (1996). A consumer`s guide to evenness indices. Oikos, 76, 70-82.

543 Theoharides, K.A., \& Dukes, J.S. (2007). Plant invasion across space and time: factors 544 affecting nonindigenous species success during four stages of invasion. New Phytologist, 176, $545 \quad 256-273$.

546 Tilman, D. (1982). Resource competition and community structure. Princeton: Princeton 547 University Press.

548 Tilman, D. (1994). Competition and biodiversity in spatially structured habitats. Ecology, 75, $5492-16$.

550 Tilman, D., Reich, R.B., \& Knops, J.M.H. (2006). Biodiversity and ecosystem stability in a 551 decade-long grassland experiment. Nature, 441, 629-632.

552 van der Werf, A., van Nuenen, M., Visser, A.J., \& Lambers, H. (1993). Contributions of 553 physiological and morphological plant traits to a species`competitive ability at high and low 554 nitrogen supply: a hypothesis for inherently fast- and slow-growing monocotyledonous 555 species. Oecologia, 94, 434-440.

556 van Ruijven, J., de Deyn, G.B., \& Berendse, F. (2003). Diversity reduces invasibility in 557 experimental plant communities: the role of plant species. Ecology Letters, 6, 910-918.

558 Wardle, D.A. (2001). Experimental demonstration that plant diversity reduces invasibility 559 evidence of a biological mechanism or a consequence of sampling effect. Oikos, 95, 161-170

560 Yurkonis, K.A., Meiners, S.J., \& Wacholder, B.E. (2005). Invasion impacts diversity through 561 altered community dynamics. Journal of Ecology, 93, 1053-1061.

562 Zavaleta, E., \& Hulvey, K. (2004). Realistic species losses disproportionately reduce 563 grassland resistance to biological invaders. Science, 306, 1175-1177. 
Figure legends

565

566 Fig. 1. Temporal variation (2003-2007) of resident species numbers (A, B), resident species

cover $(C, D)$, resident community cover $(E, F)$, resident community biomass $(G, H)$. In the

568 left panels, means of CVs $( \pm$ SE) are plotted against sown species richness for weeded and

569 non-weeded subplots (A, C, E, G). In the right panels, lnRR-values are shown representing

$570 \log$ response ratios between non-weeded and weeded subplots. They are given as means $( \pm$

571 SE) for each sown species-richness level per study year (B, D, F, H). Positive lnRRs indicate

572 that values were larger in non-weeded subplots compared to weeded subplots, while negative

$573 \operatorname{lnRRs}$ indicate the opposite. Significance of overall means $\neq 0$ across all species-richness

574 levels was tested separately for each study year, where $\mathrm{ns}=$ non-significant, $* \mathrm{p} \leq 0.050$, ** $\mathrm{p}$

$575 \leq 0.010, * * * \mathrm{p} \leq 0.001$

576

577 Fig 2. The log response ratio $(=\operatorname{lnRR})$ of the number of germinating resident species (A), and

578 the log response ratio of seedling densities of resident species (B) based on three censuses in

5792006 (April, July, October) plotted against sown species richness. Bars represent means per

580 species-richness level ( \pm SE, for symbols see Fig. 1). Positive lnRRs indicate that numbers of 581 germinating species and resident seedling densities were higher in non-weeded than in 582 weeded subplots, while negative lnRRs indicate the opposite.

584 Fig. 3. Compositional dissimilarity (Bray-Curtis distances) of resident species combinations 585 between pairs of weeded and non-weeded subplots by species-richness level (mean \pm SE) and 586 year. Values are based on two cover estimates (before the first (May) and second (August) 587 mowing, respectively). 
589 Fig. 4. Temporal variation (2003-2007) of year-to-year changes (= Bray-Curtis distances) in

590 resident species composition (A, B), Shannon evenness J of resident species combinations

591 (C, D), Simpson index of evenness $E_{1 / D}$ of resident species combinations (E, F), functional

592 trait diversity $\mathrm{FD}_{\mathrm{Q}}(\mathrm{G}, \mathrm{H})$. In the left panels, means of CVs $( \pm \mathrm{SE})$ are plotted against sown

593 species richness for weeded and non-weeded subplots (A, C, E, G). In the right panels, lnRR-

594 values are shown representing log response ratios between non-weeded and weeded subplots.

595 They are given as means $( \pm$ SE) for each sown species-richness level per study year $(B, D, F$,

596 H). Positive lnRRs indicate that values were larger in non-weeded subplots compared to

597 weeded subplots, while negative lnRRs indicate the opposite. Significance of overall means $\neq$

5980 across all species-richness levels was tested separately for each study year, where ns $=$ non-

599 significant, $* \mathrm{p} \leq 0.050, * * \mathrm{p} \leq 0.010, * * * \mathrm{p} \leq 0.001$. For symbols see Fig. 1 .

600

601 Fig. 5. Cover of colonizer species plotted against sown species richness (A) and year (B), and

602 colonizer species numbers plotted against sown species richness (C) and year (D) in weeded

603 subplots before weeding (mean values for data recorded before spring- and summer-weeding)

604 and mowing (mean values for data recorded before early- and late-summer mowing) and non-

605 weeded subplots before mowing. Values are means ( \pm SE) per species-richness level across

606 study years (2003-2007) in the left panels, and means ( \pm SE) across all species-richness levels

607 per study year in the right panels.

608 
Table 1. Summary of mixed effects model analyses of coefficients of variation for resident species cover and log response ratios of resident species cover (lnRR comparing non-weeded vs. weeded subplots) based on a five-year study period (2003-2007)

\begin{tabular}{|c|c|c|c|c|c|}
\hline & \multicolumn{2}{|c|}{ CV Species cover } & & \multicolumn{2}{|c|}{ In RR Species cover } \\
\hline & $\mathrm{L}$ ratio & $\mathrm{p}$ & & $\mathrm{L}$ ratio & $\mathrm{p}$ \\
\hline SR (log-linear) & 19.92 & $<0.001 \downarrow$ & SR (log-linear) & 29.05 & $<0.001 \uparrow$ \\
\hline Species ID & 806.33 & $<0.001$ & Species ID & 89.86 & 0.006 \\
\hline Functional group ID & 14.03 & 0.003 & Functional group ID & 4.10 & 0.251 \\
\hline Legume & 6.25 & $0.012 \uparrow$ & Legume & 0.25 & 0.617 \\
\hline Grass & 0.29 & 0.208 & Grass & 2.10 & 0.147 \\
\hline Small herb & 11.8 & $0.001 \downarrow$ & Small herb & 0.03 & 0.867 \\
\hline Tall herb & 0.2 & 0.657 & Tall herb & 3.22 & 0.073 \\
\hline Weeding Treatment $(\mathrm{W})$ & 4.51 & $0.034 \uparrow$ & Year & 22.44 & $<0.001 \downarrow$ \\
\hline$S R \times W$ & 1.29 & 0.256 & SR $\times$ Year & 9.04 & 0.003 \\
\hline Species ID x W & 19.69 & 1.000 & Species ID x Year & 78.06 & 0.049 \\
\hline Functional group ID $\times$ W & 0.21 & 0.977 & Functional group ID x Year & 1.91 & 0.592 \\
\hline Legume $\times$ W & $<0.01$ & 0.955 & Legume x Year & 1.42 & 0.234 \\
\hline Grass $\times$ W & 0.11 & 0.743 & Grass x Year & 0.06 & 0.801 \\
\hline Small herb $\times \mathrm{W}$ & 0.15 & 0.699 & Small herb $x$ Year & 0.58 & 0.446 \\
\hline Tall herb $\times \mathrm{W}$ & 0.01 & 0.915 & Tall herb $x$ Year & 0.44 & 0.509 \\
\hline
\end{tabular}

Models were fitted by stepwise inclusion of fixed effects. Likelihood ratio tests were applied to assess model improvement ( $\mathrm{L}$ ratio) and the statistical significance of the explanatory terms (p values). Significant effects are marked in bold. Arrows indicate increase $(\uparrow)$ or decrease $(\downarrow)$ of the variables with species richness, dependent on functional group identity or time. SR = sown species richness. 
Figure 1
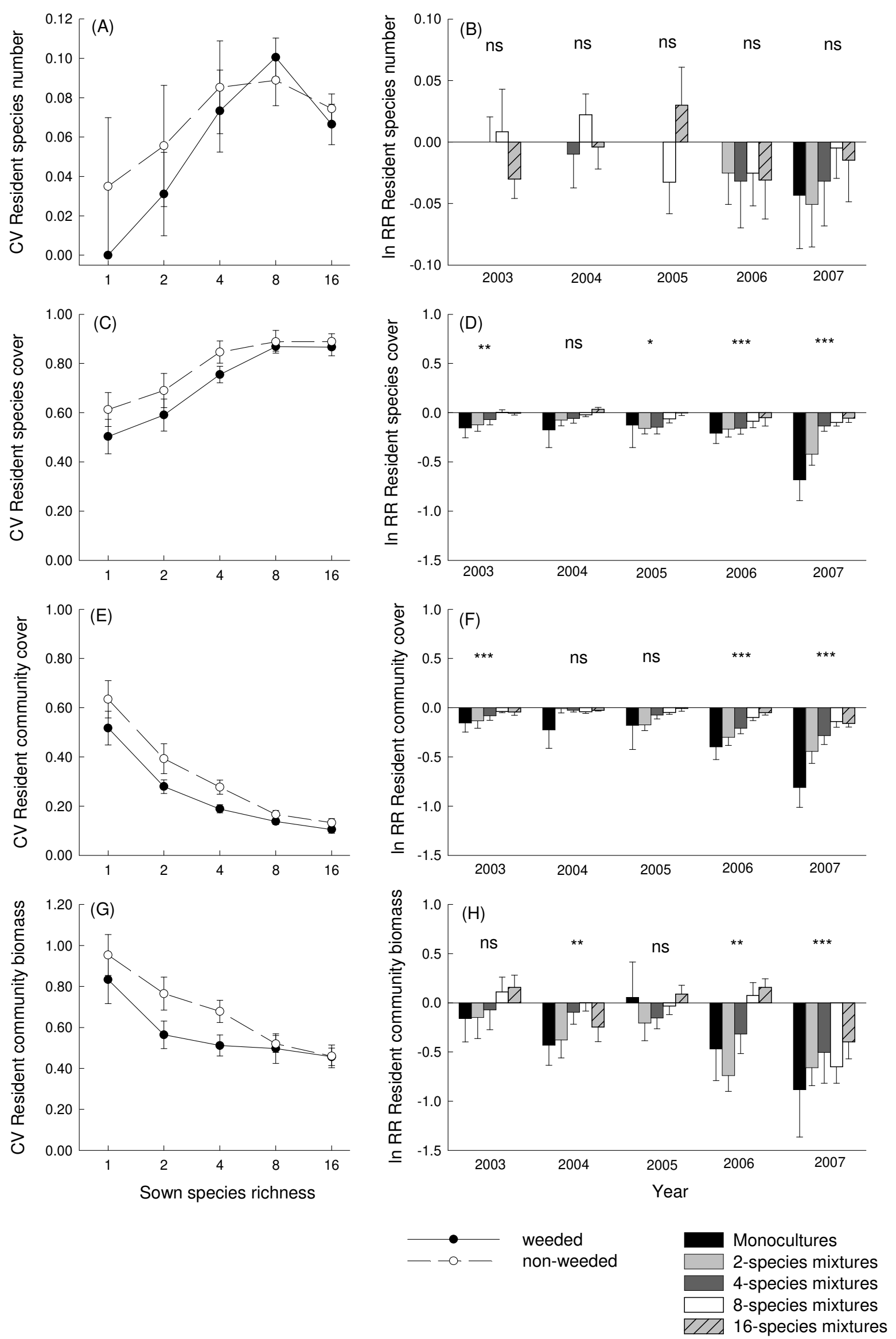
Figure 2
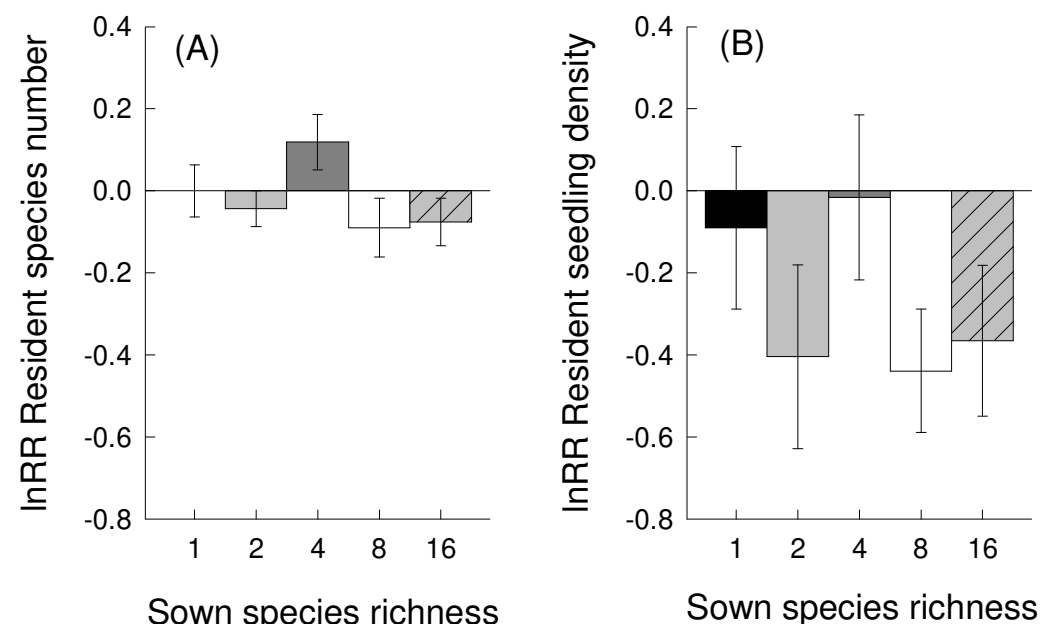

Sown species richness 
Figure 3

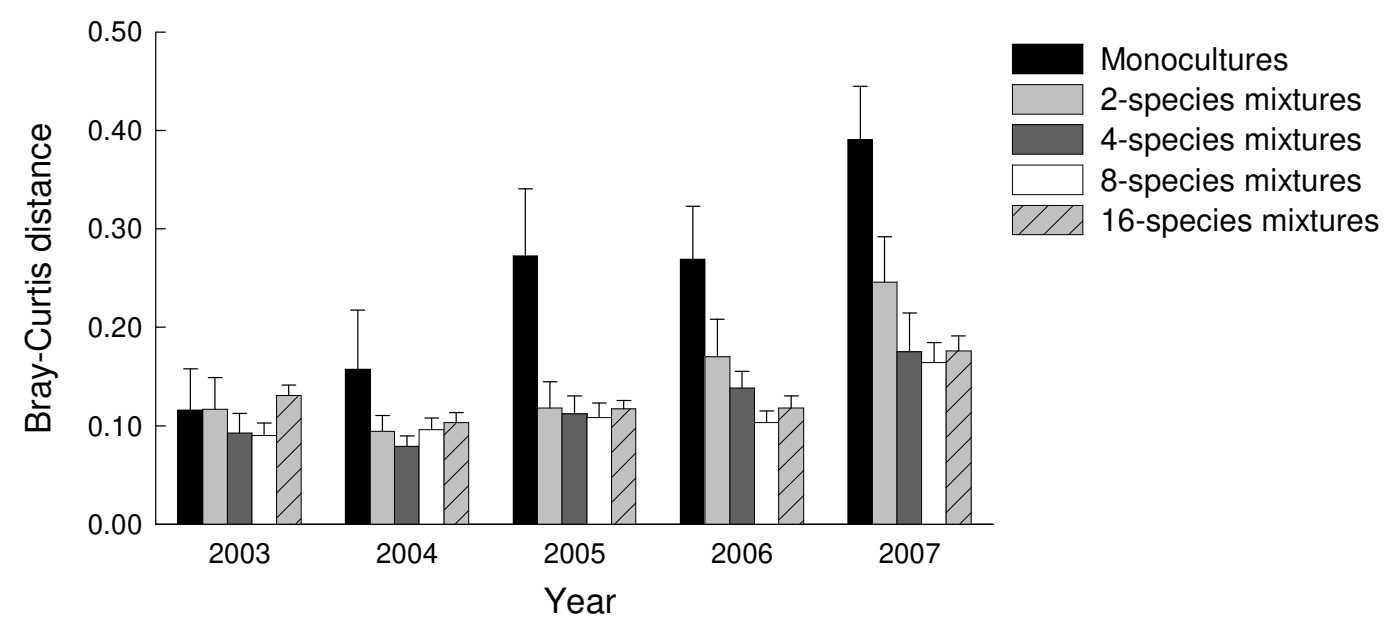


Figure 4
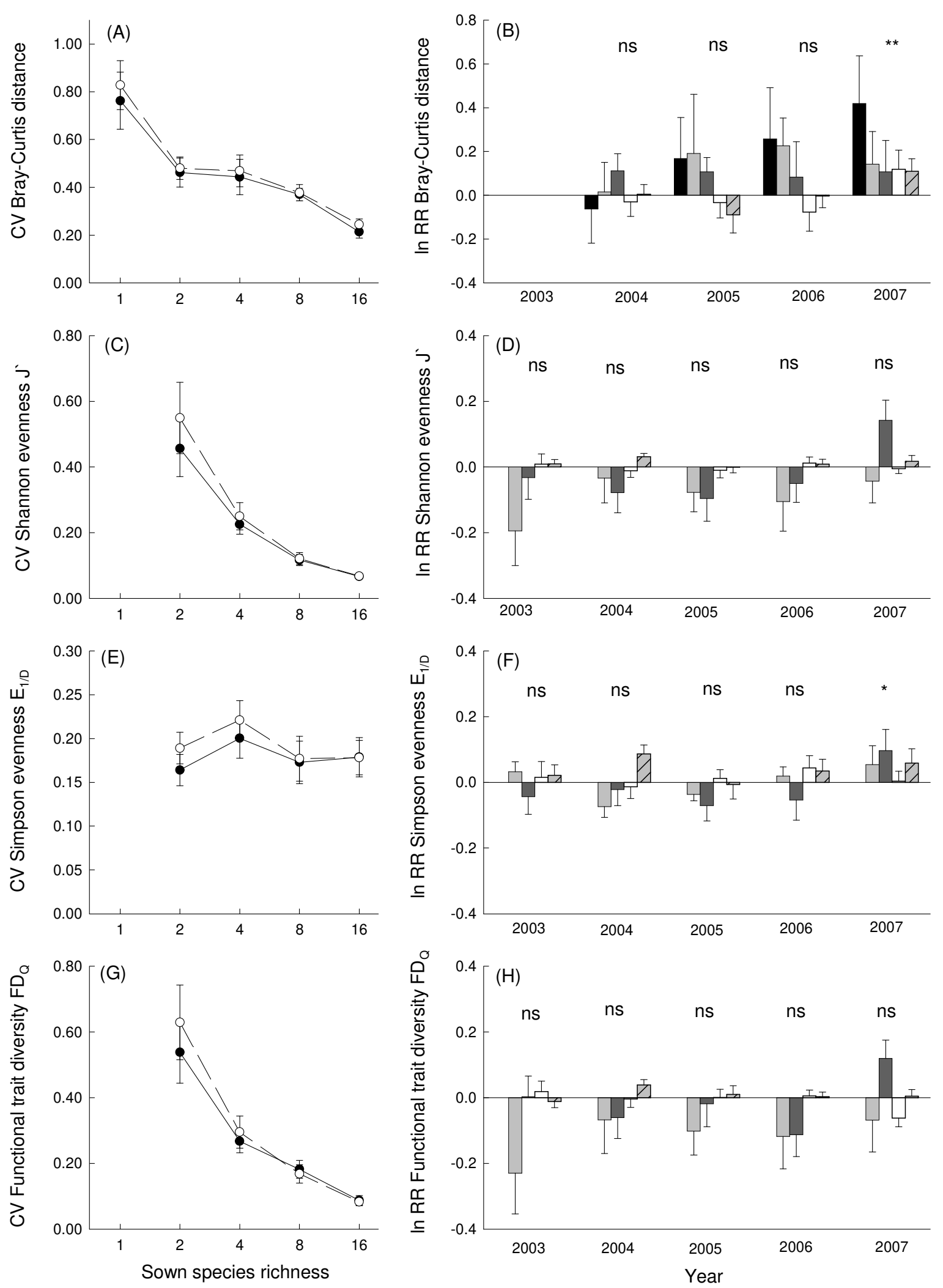
Figure 5
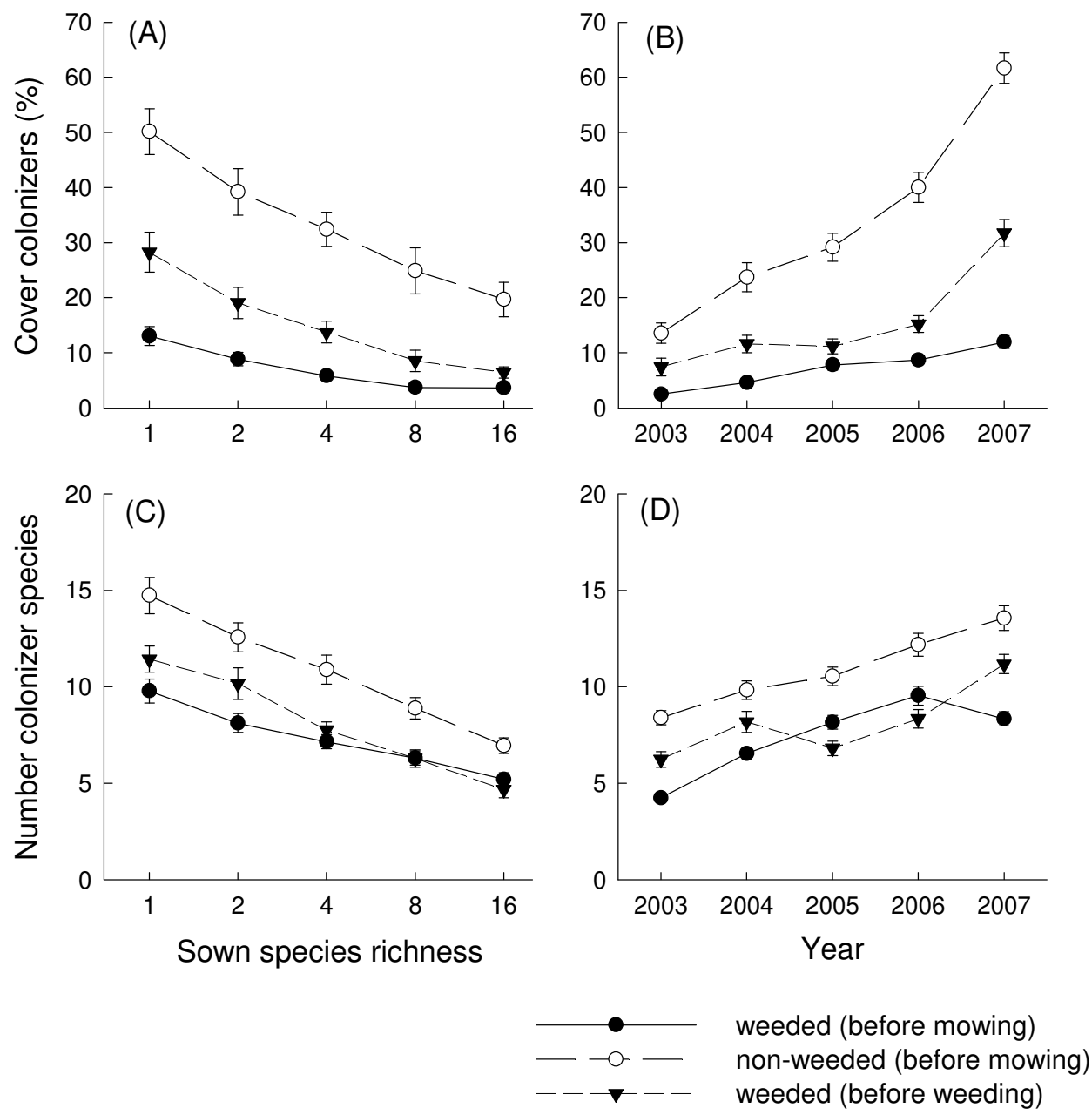